IMAGINARIOS SOCIALES SOBRE USO DE TECNOLOGÍA

Y RELACIONES INTERPERSONALES EN JÓVENES UNIVERSITARIOS

A TRAVÉS DEL CINE DE FICCIÓN COMO RECURSO DIDÁCTICO

Social imaginaries about the use of technology

and interpersonal relationships in university students

through fiction films as a didactic resource

\author{
Julio Cuevas Romo* \\ Universidad de Colima, México \\ jcuevas0@ucol.mx \\ Código Orcid: http://orcid.org/0000-0003-1325-4029
}

\begin{abstract}
Resumen
A partir del uso del cine de ficción como recurso didáctico, se expone una experiencia educativa con estudiantes de la Licenciatura en Enseñanza de las Matemáticas, que participaron en un ciclo de cine-debate centrado en ciencia ficción y mundos posibles. Múltiples han sido los abordajes que se han dado al cine dentro de los procesos educativos, sin embargo, para consolidar y sistematizar este potencial, se propone una categorización en función de los objetivos didácticos partiendo de los usos más comunes. A través de observar la película Her, se analizan los imaginarios sociales de los jóvenes respecto al uso y abuso de la tecnología, y cómo esto impacta en las relaciones interpersonales. La metodología de trabajo se centra en lo propuesto por Torres (2015) como conceptualización de imaginario social y su potencial dentro de los procesos de intervención educativa, complementado con la construcción de instrumentos de pregunta abierta propuestos por Pérez-Millán (2014) para el análisis de productos audiovisuales. Los resultados corroboran algunos aspectos respecto a la postura de los jóvenes en cuanto a los espacios virtuales de socialización y su repercusión en los espacios presenciales, en investigaciones previas como las de Ruelas (2013) o Sosa (2018). Los imaginarios sociales que se detonan a partir de las narrativas ficticias como el cine, sirven de base para realizar intervenciones educativas específicas.
\end{abstract}

Palabras clave

Narrativa, imaginario social, tecnología de la comunicación, material didáctico, educación alternativa.

Forma sugerida de citar: Cuevas, Julio (2020). Imaginarios sociales sobre uso de tecnología y relaciones interpersonales en jóvenes universitarios a través del cine de ficción como recurso didáctico. Sophia, colección de Filosofía de la Educación, 28(1), pp. 165-183.

* Doctor en Educación por la Universidad de Guadalajara. Actualmente es profesor-investigador de tiempo completo en la Facultad de Ciencias de la Educación de la Universidad de Colima donde coordina la Maestría en Intervención Educativa. Miembro del Sistema Nacional de Investigadores desde el año 2012. Líneas de investigación: procesos de enseñanza y aprendizaje de ciencias y matemáticas en contextos de diversidad y vocaciones científicas. 


\begin{abstract}
From the use of fiction cinema as a teaching resource, an educational experience is exposed with students of the Bachelor of Mathematics Teaching who participated in a film debate cycle focused on science fiction and possible worlds. Multiple have been the approaches that have been given to the cinema within the educational processes, however, to consolidate and systematize this potential, a categorization is proposed based on the didactic objectives starting from the most common uses. Through observing the film Her, the social imaginaries of young people are analyzed regarding the use and abuse of technology and how this impacts on interpersonal relationships. The work methodology focuses on what Torres (2015) proposed as a conceptualization of social imaginary and its potential within the processes of educational intervention, complemented by the construction of open question instruments with the proposed by Pérez-Millán (2014) to the analysis of audiovisual products. The results corroborate some aspects regarding the position of young people, regarding virtual spaces of socialization and their impact on face-to face spaces in previous research as Ruelas (2013) or Sosa (2018). Social imaginaries that are detonated from fictional narratives such as cinema can be used to carry out specific educational interventions.
\end{abstract}

Keywords

Narrative, social imaginary, communication technology, teaching material, alternative education.

\title{
Introducción
}

Lejos han quedado las perspectivas o posturas educativas que ubicaban los productos audiovisuales — principalmente la televisión- como el enemigo a vencer. Actualmente es imposible hablar de las consecuencias negativas o positivas de estos productos per se, más bien se trata, desde una postura crítica, de analizar el potencial reflexivo y educativo que la televisión, el cine o el streaming pueden tener.

En los siguientes apartados se describe la postura respecto al uso de medios audiovisuales, en particular el cine, para educar, reflexionar y conocer cómo se perciben ciertos aspectos de la realidad, en este caso con jóvenes estudiantes de licenciatura, planteando como objetivo conocer sus imaginarios sociales respecto al uso actual de la tecnología, en particular los teléfonos inteligentes, los espacios virtuales y sus consecuencias.

En el primer apartado se describe una sistematización y clasificación básica del cine como recurso didáctico, reconociendo sus principales características y los usos más comunes. El en segundo apartado se aborda la postura teórica de la investigación, tomando como elemento central el concepto de imaginario social y su vinculación con la educación desde una postura constructivista de aprendizaje. En el tercer apartado se describe la selección de la película Her como recurso didáctico para intervenir con los estudiantes, mencionando y explicando su pertinencia para detonar los imaginarios sociales de interés. El cuarto apartado describe el perfil del grupo participante y cómo se lo integró. En el quinto apartado 
se explica la metodología de análisis fundamentada en la propuesta de Pérez-Millán (2014). Finalmente, en los dos últimos apartados, se plasman algunas pautas y reflexiones sobre la intervención.

\section{El cine de ficción como recurso didáctico}

Para Wood y Gudiño (2017a) no está dada como tal una definición de lo que es el cine educativo o el rol del cine en los procesos de enseñanzaaprendizaje. Por otra parte, es innegable que todos, o casi todos, se han encontrado con docentes que en algún momento de sus clases recurrieron a una película para enseñar, ejemplificar o enfatizar algo relacionado a los contenidos de su materia. Partiendo de lo anterior, puede resultar entonces irrelevante tratar de encontrar una definición universal sobre lo que es el cine educativo, pero sí puede ser de gran utilidad considerar el uso o usos educativos que puede darse a las películas, tanto ficticias como documentales. En los últimos años se ha generado la necesidad de seguir buscando didácticas operativas para el cine en los procesos educativos, pasando de la divulgación a procesos pedagógicos más específicos, algo que, por fortuna, muchos profesores, divulgadores e investigadores están tratando de consolidar.

Hay diversos autores que se han dado a esta tarea. Existen pues, múltiples usos, enfoques y por tanto categorías y debates sobre la intencionalidad del cine como recurso de enseñanza o didáctico. En menor medida, pero también con este propósito, se han hecho sistematizaciones similares a otros formatos de productos mediáticos en los procesos de enseñanza como el cómic o más recientemente las series streaming de plataformas como Netflix o Amazon Prime. Se considera que, aunque existen diferencias significativas entre los formatos de cine, streaming o cómic, para fines educativos y en particular de este aporte, el proceso de análisis que aquí se presenta puede aplicarse a cualquiera de estos productos, vistos todos como narraciones secuenciadas donde predominan las imágenes.

En otra época se decía que la televisión (o el cine) educaba o mejor dicho mal educaba, pues este argumento solía darse en connotación negativa. Esta percepción, muchas veces transformada en prejuicio, se ha ido diluyendo, en buena parte, al considerar que los medios audiovisuales no son el elemento a vencer por parte del sistema educativo, sino que es necesaria una educación para los medios. De aquí se desprende también el análisis sobre la intencionalidad en el uso de estos formatos-productos en los procesos educativos. Esta intencionalidad puede darse en dos formas. 
La primera incluye a los productos o en este caso las películas que desde su producción pretenden educar, es decir, fueron realizadas con esa finalidad. Estas películas no se centran exclusivamente en el género documental, sin embargo, sí son las más representativas o, en todo caso, utilizadas por considerarse más objetivas o alejadas de la ficción intencional. Si bien el cine documental pretende mostrar una realidad a partir de hechos capturados de forma audiovisual, a fin de cuentas la presenta de forma editada, segmentada y con uno o varios objetivos ideológicos específicos e intencionales, pues el propósito es convencer a la audiencia. Los realizadores muestran un mensaje interpretativo para el receptor o bien una tendencia al adoctrinamiento. Aun así, es considerado un producto con mayor fidelidad a la realidad cotidiana que el cine de ficción.

La segunda intencionalidad se refiere a las películas que no fueron concebidas para enseñar o educar, pero que pueden usarse para este fin. En esta segunda intencionalidad es donde se ubican las narrativas audiovisuales pertenecientes a géneros de ficción, al que pertenece la película que interesa en este caso, Her, dirigida por Jonze en el año 2013. Para fines de este trabajo, el género de ficción requiere también una clasificación básica que, de acuerdo a lo planteado por Wood y Gudiño (2017b, 2017c), podría identificar dos categorías centrales.

Por una parte está el cine de ficción ubicado en una realidad identificable, en donde entran películas biográficas o reinterpretaciones de periodos históricos, pero que tienen la intención de ser fieles a la realidad como Bohemian Rhapsody (Singer, 2018), Lincoln (Spielberg, 2012) o The Imitation Game (Tyldum, 2014). También dentro de esta categoría se pueden ubicar películas que si bien no se centran en biografías específicas, sí se enlazan directamente con pasajes históricos totalmente identificables y se realizan en un contexto que muestra algunas características de un periodo histórico específico, como el caso de Gladiator (Scott, 2000), Inglourious Bastards (Tarantino, 2009) o El laberinto del Fauno (Del Toro, 2006). Esta última, pese a ser ya un clásico del género de fantasía, ilustra de manera muy clara y acertada algunos elementos del contexto de la postguerra civil española.

Por otra parte, siguiendo con las narrativas ficticias, está el cine de ficción que se encuentra ajeno a una realidad identificable, destacando principalmente los géneros de fantasía o ciencia ficción. Aunque, en efecto, no fueron pensados como productos educativos, su potencial de reflexión o de aprendizaje se da en función de lo que alegorizan, según lo exponen Mejía y Nahmad (2017). Resignifican la realidad a partir de la creación de otros mundos y quien los consume, los observadores, saben 
que lo que se está viendo no es real, pero centran su atención en la verosimilitud a partir de la coherencia interna y la narrativa del mundo creado por los autores (algo muy similar a la literatura). Para el caso del cine de fantasía se pueden ubicar ejemplos muy conocidos como The Chronicles of Narnia: The Lion, the Witch and the Wardrobe (Adams, 2005). Esta - como muchas historias plagadas de elementos fantásticos- alegoriza situaciones o dilemas identificables como la búsqueda del poder, las relaciones parentales o la crudeza de la guerra y su impacto en los niños. En cuanto al cine de ciencia ficción es pertinente realizar una subdivisión para ayudar a entender el potencial didáctico o educativo que puede aportar. En primera instancia, se encuentran las películas que pertenecen a otro género como comedia, terror, aventura o drama, pero que incorporan elementos identificables de ciencia para el desarrollo de sus tramas. Ejemplos concretos son Inception (Nolan, 2010), Terminator (Cameron, 1984) o Star Trek (Abrahams, 2009), aunque esta última, de forma no intencional según sus propios creadores, ha sido una de las más acertadas en predecir avances tecnológicos reales desde la década de los 60 como la telefonía celular, las pantallas interactivas, la resonancia magnética o incluso algunos fundamentos de los viajes interestelares. Este conjunto de películas, aunque lejos de elementos científicos o tecnológicos posibles como pueden ser viajes en el tiempo, teletransportación o tecnología autónoma, curiosamente son las que más se han utilizado para la enseñanza. ¿¿Por qué? Muy probablemente, más allá de su popularidad, se debe a que, presentando elementos claramente inverosímiles desde los hechos científicos, son precisamente una excelente excusa para la contra argumentación. ¿Por qué nadie puede brincar como lo hace Hulk? ¿Por qué es imposible que exista un ser del tamaño de Godzilla? ¿Por qué no puede haber explosiones en el espacio como en Star Wars? ¿Por qué se puede viajar al futuro como lo planteaba Stephen Hawking, mas no al pasado como sucede en las películas de Edge of Tomorrow o Terminator? Estas ideas, tan aceptadas mientras son observadas en pantalla, pero tan lejanas cuando las discutimos como algo realmente posible, son sencillas de comparar con la tecnología y la ciencia conocida, por lo tanto, requieren precisamente un mínimo de nociones para poder ser refutadas, sobre todo cuando uno discute en cursos introductorios a las disciplinas científicas o con estudiantes de niveles básicos.

Siguiendo con la ciencia ficción, se tiene el otro extremo, es decir, las películas que, si bien es cierto tienen una carga relevante de elementos ficticios, la parte medular de su trama gira en torno a fenómenos muy cercanos a nuestra realidad. Películas como The Martian (Scott, 2015), 
Gravity (Cuarón, 2013) o 2001: A Space Odyssey (Kubrick, 1968) son claros ejemplos de esto al abordar de forma muy realista cuestiones relativas a los viajes espaciales.

Estos filmes colocan al espectador, por lo general, en futuros cercanos reconocibles y suelen ser asesorados, tanto en el guion como en la parte visual, por científicos de renombre, como es el caso de Kip Thorne, Premio Nobel de Física, quien participó directamente en películas como Contact (Zemeckis, 1997) o Interestelar (Nolan, 2014), ambas como claros ejemplos de fidelidad narrativa en términos de física, astronomía y relatividad. El potencial didáctico, en este caso, es el inverso a la contra argumentación. Se centra en la discusión y la reflexión sobre posibilidades reales de lo que el espectador observa de acuerdo al área de conocimiento o contenidos que se desean abordar. A diferencia de la contra argumentación, su uso y potencial didáctico es recomendado para estudiantes que ya poseen cierto dominio de la temática.

Ambas subdivisiones, argumentación y contra argumentación desde las películas de ciencia ficción, poseen su potencial didáctico en el abordaje de contenidos ligados a ciencia y tecnología más de carácter disciplinar. En la Figura 1 se puede revisar un diagrama sintetizado del potencial didáctico de las narrativas audiovisuales desde el cine, en función de su intencionalidad.

Para el caso que interesa en este aporte, las reflexiones que los estudiantes puedan derivar de observar y discutir la película Her, se podría colocar en la categoría de las que reflejan una realidad muy cercana a nuestra cotidianidad, nuestro presente o futuro próximo. Sin embargo, podemos referir a una tercera subdivisión para el uso didáctico del cine de ciencia ficción, independientemente de si los filmes en cuestión pertenecen a cualquiera de los géneros ficticios ya mencionados.

Es aquí donde cobra relevancia el concepto de 'imaginarios sociales', los cuales pueden identificarse a partir de observar y analizar las películas como un recurso didáctico detonador. Los imaginarios ilustran posturas y comportamientos ligados a nuestras acciones como seres humanos, de ahí que prácticamente cualquiera de las películas anteriormente mencionadas pueda ser útil.

¿Qué tipo de perfil tienen los científicos, tecnólogos y usuarios que aparecen en las narrativas? ¿Quiénes y cómo utilizan la tecnología? ¿Con qué variaciones? ¿En qué consiste su actividad? ¿Cuáles son las motivaciones de los personajes? ¿Qué dificultades y dilemas éticos enfrentan? En específico: ¿Qué características de nuestra realidad son identificables en personajes ficticios cuyas acciones nos son familiares, ya sea por identifi- 
cación o rechazo? ¿Bajo qué principios éticos y qué tipo de usos se le da a la tecnología en estas determinadas historias?

Figura 1

Esquematización del potencial didáctico del cine

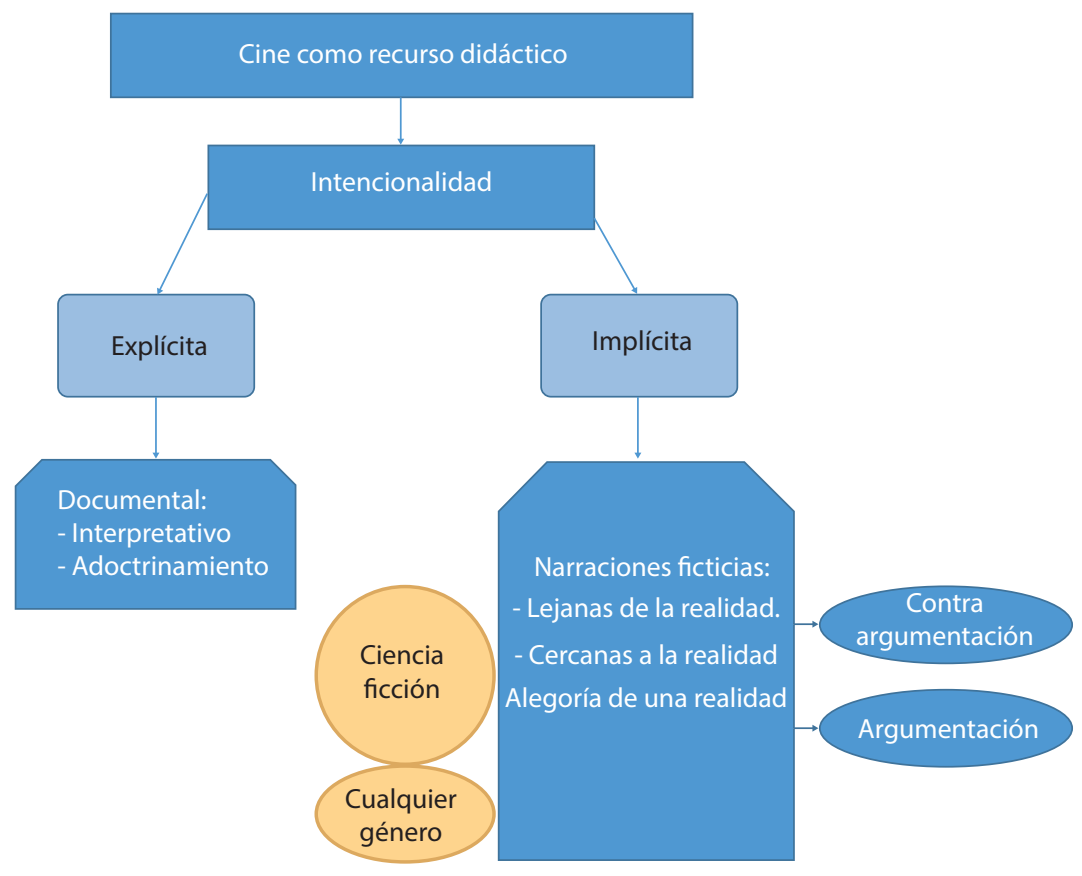

Elaborado por: El autor

En este aporte se analizan los imaginarios sociales sobre el uso de tecnología, particularmente la de los teléfonos inteligentes y su repercusión en las relaciones interpersonales expuestos por un grupo de estudiantes universitarios pertenecientes a la Licenciatura en Enseñanza de las Matemáticas, a partir de observar la película Her. Para esto se brindan, primero, algunos elementos básicos sobre el concepto de imaginario social, así como las categorías propuestas por Pérez-Millán (2014) para el análisis de material audiovisual.

\section{Imaginario social}

El quehacer científico y tecnológico ha sido representado de múltiples formas en el cine, la televisión y el cómic. Muchas de estas representacio- 
nes van generando creencias, estereotipos y, por consecuencia, actitudes de quienes consumen estos productos de comunicación visual o audiovisual. Esto, en parte, va influyendo en su postura hacia las vocaciones científicas y a la forma en que se apropian, reinterpretan o rechazan el constructo del quehacer científico o tecnológico.

Hay una intencionalidad explícita de quienes realizan una serie de televisión, película o cómic, de transmitir un mensaje, establecer una comunicación con el receptor. Los observadores activos, al consumir el producto, están optando por establecer esa comunicación, ya sea integrando, reconstruyendo o rechazando el mensaje a su esquema cognitivo personal, como se plantea en los principios constructivistas del aprendizaje. Este proceso está mediado por las experiencias previas y las expectativas que el sistema social les ha generado. En este sentido, el concepto de imaginario social es útil para entender cómo este proceso cargado de contexto, sobreentendidos y prejuicios, es naturalizado, como lo comenta Torres (2015).

El concepto de imaginario social, de acuerdo con Randazzo (2012), ha sido ambiguo, por ende, su utilización también. Algunas veces es entendido como la ideología, la cosmovisión, la conciencia colectiva, la percepción o la mentalidad, derivando en un problema de falta de rigurosidad, al menos a nivel conceptual y metodológico, generando interpretaciones intuitivas. Es necesario, entonces, delimitarlo y trabajarlo sistemáticamente.

Desde el campo científico educativo es pertinente acudir a las perspectivas de enseñanza-aprendizaje, por lo que la definición que plantea Pintos (2015), quien ubica a los imaginarios sociales como esquemas construidos socialmente que pueden orientar nuestra percepción, permitir nuestra explicación y hacer una posible intervención en lo que en los diferentes sistemas sociales se ha tenido como realidad, es bastante útil.

Para quienes estén familiarizados con teorías pedagógicas, la noción de esquemas y construcción de conocimiento sin duda les recordará los planteamientos constructivistas del aprendizaje. Sin afán de entrar en debate entre las dos grandes líneas que derivan del aprendizaje desde el constructivismo - como lo son el constructivismo sociocultural planteado por Lev Vygotsky y el constructivismo psicogenético de Piaget-, los esquemas de construcción de conocimiento hacen sentido en cuanto a que los aprendizajes previos que se tienen respecto a cualquier concepto, se encuentran en permanente reconstrucción en función de las nuevas experiencias y aprendizajes, en algunas ocasiones incorporando lo nuevo a dichos esquemas previos y en otras ocasiones rechazándolo y manteniendo o reforzando los esquemas como están. 
Así, la definición de Pintos no solo es útil y pertinente, sino que nos posiciona en una postura constructivista del aprendizaje, a la vez que es compatible con lo argumentado por Torres (2015), quien dice que los imaginarios sociales son simplificaciones comunicativas, las cuales pueden servir como un detonador, en este caso un mensaje audiovisual que se conecta con nuestro esquema de conocimiento previo, ya sea para incorporar la nueva información, reinterpretarla o rechazarla.

El imaginario social tiene que ver con las diversas visiones del mundo, constituyéndose como forma, en constante cambio, de expresión y mecanismo indirecto de reproducción. Genera consecuencias de identidad colectiva y de ahí la pertinencia de voltear a los productos y representaciones mediáticas que reflejan, pero al a vez construyen una realidad identificable, ya sea en términos cotidianos o por medio de la alegoría.

En concreto, por ejemplo, al ver alguna película, se puede pensar en el imaginario social que pueda tenerse sobre la tecnología, sus usos y sus consecuencias. En todos existe un imaginario sobre la tecnología y su impacto en la vida cotidiana, ya sea desde la experiencia como usuarios (a nivel interno) o el cómo se percibe de otros usuarios (a nivel externo), así como los impactos positivos o negativos que se piensa que genera.

Se tiene una serie de suposiciones, comportamientos y normas sociales sobre la tecnología que se usa a diario, en específico para comunicarse e interactuar. ¿Qué sucede cuando se expone a partir de una narrativa específica, a un tipo o tipos de usuarios que cumplen con esas suposiciones y normas? O bien, en sentido contrario, ¿qué se detona si se observa que alguien desafía esas normas o las lleva al extremo? No se puede, en efecto, mostrar en su totalidad, de golpe, todas esas suposiciones que guían la acción de un usuario frente a la tecnología, sin embargo, sí es posible plantear ciertas situaciones en donde las implicaciones de ese uso se puedan visibilizar. Se puede pensar en una película de carácter realista y dramático como The Social Network (Fincher, 2010) o de tintes políticos como Snowden (Stone, 2016); ambas narrativas advierten en cierta medida del fenómeno a gran escala de comunicación mediado por tecnología que se vive actualmente, pero las narrativas se presentan lejanas desde el punto de vista de los usuarios.

En este sentido, el temor de peligros derivados de la dependencia de la tecnología para interactuar, representada en productos como la serie británica Black Mirror (2011) de la plataforma Netflix, tiene un impacto mucho mayor, pues siempre son los usuarios comunes los que sufren los usos y abusos tecnológicos en narrativas que van desde la comedia hasta el horror, pero siempre con consecuencias negativas por los excesos y depen- 
dencia de la tecnología en la cotidianidad. Este tipo de fenómenos no es nuevo, por supuesto; por ejemplo, en la década de los 60, abundaron narrativas audiovisuales que reflejaban el temor a una posible guerra atómica en el marco real de la Guerra Fría y la proliferación de armas nucleares.

En estas narrativas, como en cualquier caso de tecnología aplicada, la inteligencia artificial o la comunicación virtual no pueden ser clasificadas como buenas o malas per se, sino que son las acciones realizadas por individuos específicos lo que detona en el espectador la postura frente a lo que está observando, la cual va de acuerdo a lo que su imaginario social posee, con todas las dimensiones antes mencionadas. Para que esa postura se materialice, debe existir previamente el 'deber ser', las reglas y normas explícitas e implícitas para que el observador pueda comparar los desafíos que estos personajes realizan a la norma establecida.

Entra en juego, entonces, al momento de establecerse la comunicación, en este caso entre el observador y la película en cuestión, el código socialmente aprendido, lo que nos sirve para construir nuestro imaginario y nuestra postura hacia las acciones que alguien realiza. Las autodescripciones que recibimos en estos productos son mostradas con la idea de ser una imagen fiel de un sistema complejo. Es decir, la complejidad global, en este caso del imaginario del uso de tecnología y su impacto en la socialización, no puede describirse, pero las narrativas desde estas simplificaciones o descripciones que se presentan, sí pueden. ¿Qué imaginario social sobre los usos y abusos de la tecnología y su repercusión en nuestra forma de socializar se identifican a partir de una narrativa ficticia? ¿Cómo se incorporan estas representaciones a los esquemas previos, o bien, las son rechazadas según sea el caso?

\section{La película Her como recurso didáctico}

Dirigida por Spike Jonze y protagonizada por Joaquin Phoenix en el papel de Theodore (quien recibió críticas muy positivas), Her (nombrada Ella en Latinoamérica) se estrenó en el año 2013. Considerada una película más de premiaciones y de halagos de especialistas antes que un éxito en taquilla, aborda la inusual relación entre un hombre común y su sistema operativo, una especie de sistema muy avanzado basado en Siri, diseño real de la empresa Apple, al que en la película da voz la actriz Scarlett Johansson.

A diferencia de películas como A.I. (Spielberg, 2001) o la más reciente I Am Mother (Sputore, 2019), en donde la relación afectiva entre 
humanos y robots se sigue presentando en un futuro distante o irreal, posiblemente lo más perturbador en $\mathrm{Her}$ es que precisamente presenta un panorama muy familiar. Sin dar fecha exacta, la narrativa nos ubica en un futuro muy cercano, con condiciones casi iguales a las presentes.

El mismo sistema operativo, lejos de diseños futuristas, nos es común, no tiene presencia física, se limita a una voz con la cual interactuar a través de un dispositivo que actualmente poseemos nuestro teléfono inteligente. El gran logro de la narrativa es, sin duda, lo natural y verosímil que puede resultar la relación sentimental progresiva del hombre con su dispositivo, mientras se aísla cada vez más de los seres humanos. No es el propósito de este aporte realizar una reseña o crítica cinematográfica, sin embargo, es importante una muy breve descripción de los personajes para que el análisis con los estudiantes pueda ser mejor comprendido posteriormente (se recomienda, por supuesto, ver el filme).

Rooney Mara, como Catherine, la exesposa de Theodore, quien se asume en la trama, aún mantiene cierto cariño por él, pero en ningún momento se arrepiente de haberse separado, es la única que reacciona con extrañeza ante la relación sentimental de Theodore con su sistema operativo. Amy Adams, como Amy, interpretando a la mejor amiga de Theodore, también recién divorciada y la que muestra más empatía con él, se sobrentiende en varias secuencias que podría sentir algo más que empatía por Theodore, nunca lo juzga negativamente, sin embargo, él la ve como una simple amistad. Chris Pratt y Laura Kai Chen, que interpretan a Paul y Tatiana, son una pareja que tiene una relación amistosa y laboral con Theodore, aunque son solidarios y respetan su nuevo estilo de vida -incluso ven normal asistir a una cita doble con Theodore y su sistema operativo sin juzgar-, no se involucran demasiado en indagar los sentimientos de Theodore, así que de alguna manera se les puede considerar una especie de amistad superficial. Además, se presenta un breve, pero ilustrativo cameo de Olivia Wilde (no se menciona el nombre del personaje), siendo una mujer que acude a una cita a ciegas con el protagonista, con resultados negativos para ambos.

Como se dijo, era importante realizar esta descripción ya que parte del ejercicio realizado con los estudiantes fue identificarse o rechazar las conductas que estos personajes presentan en la narrativa. Como producto de ciencia ficción, a fin de cuentas, no se trata de la tecnología, sino de analizarnos a nosotros mismos, los humanos, en nuestro presente, en cómo vislumbramos el futuro, cómo nos relacionamos y nuestra capacidad de lidiar con ello. 


\section{Grupo participante}

Los 12 estudiantes participantes en este proyecto cursan la Licenciatura en Enseñanza de las Matemáticas, entre cuarto y sexto semestre, en la Facultad de Ciencias de la Educación de la Universidad de Colima. Aunque este análisis se centra en los imaginarios del uso de tecnología y su impacto en la socialización, es importante mencionar que asistieron durante todo un ciclo dedicado al cine de ciencia ficción denominado Mundos Posibles, centrado en películas con narrativas utópicas y distópicas, tanto actuales como de hace varias décadas.

Este ciclo fue organizado en conjunto con la Casa del Archivo Histórico del Municipio de Colima, lugar donde se realizaron las diez proyecciones durante el periodo enero-julio de 2019. Si bien los estudiantes son los que realizaron el proceso formal de seguimiento, es decir, responder los instrumentos escritos, la proyección de las películas fue abierta, así que tuvieron oportunidad de escuchar opiniones externas al grupo e interactuar con otro tipo de audiencia. La participación fue por invitación abierta y todos se incorporaron por interés.

\section{Metodología e instrumentos}

El reto metodológico para tener un acercamiento a los imaginarios sociales de los estudiantes a partir de observar la película, requiere en primera instancia la selección de un detonador audiovisual, para posteriormente realizar la indagación desde la narrativa (simplificada) de la película, la cual, como ya se mencionó, no presenta la problemática en todas sus dimensiones y complejidad, pero sí puede describir sus impactos o consecuencias en los protagonistas, lo cual puede a su vez provocar autodescripciones en el espectador, posibilitando las explicaciones y posturas de lo socialmente aprendido, experiencias o conocimientos previos que se detonan.

Para explorar lo anterior, se agruparon algunas de las categorías propuestas por Pérez-Millán (2014) para el análisis de material audiovisual, omitiendo las categorías técnicas, quedando como resultado dos ejes de análisis:

- Lectura de sentido. Referido a las reglas internas del universo ficticio y la coherencia interna de la narración. Incluye el conjunto de valores implícitos que la audiencia acepta como verdaderos para la narrativa.

- Motivaciones de los personajes. Referido a lo que cada personaje busca en lo individual y en su caso, a nivel colectivo. Su respeto 
o bien, desdén por las reglas o valores internos mencionados en el punto anterior, además de la forma en que interactúa con el resto de los personajes. Aquí se vislumbra también la identificación personal con alguno o algunos de los personajes, incluyendo el reconocimiento de vivencias o circunstancias, aunque no necesariamente con sus reacciones dentro de la historia.

El diseño estuvo enmarcado, como ya se mencionó, en un ejercicio dentro de un ciclo de debates más amplio que abarcó diez sesiones de cine con su respectiva discusión, el cual constó de tres etapas:

- La primera de las etapas, fue la aplicación de un cuestionario de cuatro preguntas abiertas previo a la proyección de Her, filme que por cierto nadie había visto. Estas preguntas no abordan la película sino el punto de vista de los estudiantes respecto a qué tanta importancia tiene la relación con la tecnología, en específico sus teléfonos celulares y las redes sociales y cómo esto afecta su cotidianidad, tanto en el aspecto positivo como en el negativo. Las preguntas se centraron en el tiempo dedicado a los espacios virtuales, el tipo de actividades que realizan en estos y cómo se relacionan con otras personas, tanto a nivel virtual como presencial, además de indagar si tienen preferencia por alguno de estos dos tipos de interacción.

- La segunda etapa consistió en la proyección de la película con un debate abierto sobre sus opiniones y su percepción sobre la cercanía o la lejanía de lo visto en la narrativa con respecto a la vida cotidiana. Si bien se abre un debate posterior a la película, este es de carácter libre e incluso, como ya se mencionó, puede participar cualquiera que asista a la proyección. No hay un eje conductor como tal, pero sí se rescatan ideas generales sobre lo que les pareció más relevante. Los estudiantes, en este caso, lo vincularon al cuestionario inicial.

- La tercera etapa fue la aplicación de un instrumento de dos bloques. El primer bloque, de nueva cuenta, con cuatro preguntas abiertas, en esta ocasión sí centradas en la película que tuvieron como objetivo central rescatar su opinión respecto a identificar situaciones específicas de la narrativa en sus vivencias actuales o recientes, ya sea como protagonistas o como observadores. El segundo bloque consistía en mostrar las siete fotografías de los protagonistas, tanto los principales como los secundarios, ya descritos en un apartado anterior, con la indicación de que 
mencionaran con cuál se identificaban más y con cuál se identificaban menos, en ambos casos dando las razones.

\section{Pautas, reflexiones y potencial didáctico}

Si bien parte del cuestionario y el bloque final de identificación con los personajes pueden abrir pauta a una sistematización de corte más cuantitativo, la riqueza del análisis en función del propósito de identificar los imaginarios sociales, se centra en los datos cualitativos derivados de las preguntas abiertas y las razones de identificación del último bloque, donde surgen las especificidades.

En este sentido y retomando los dos ejes derivados de la propuesta de Pérez-Millán, la lectura de sentido y las motivaciones de los personajes, sí fueron referenciados en su mayoría (10 de los 12 casos) a vivencias y posturas personales, algo muy notorio en sus argumentos, pues estos 10 estudiantes trataban de ponerse en el lugar de los caracteres, o en su caso, exponiendo hipotéticas reacciones, 'lo que hubieran hecho en el lugar de.... Los otros dos, no es que no se hayan autorreferenciado, sino que se dio de una forma más sutil, emitiendo juicios o valoraciones en tercera persona.

Cabe señalar que, si bien la película plantea el 'más allá' de las relaciones virtuales, es decir, la relación humano-sistema operativo desde lo afectivo, solo dos consideraron esto posible. Aproximadamente la mitad de los participantes piensa que ese tipo de relación no es ni será posible, la otra mitad plantea que tal vez en un futuro lejano pero bajo circunstancias que aún suenan imposibles como la capacidad de expresión de afecto por parte de una máquina. Esto es importante, puesto que, en esta narrativa, como en muchas otras que abordan la inteligencia artificial y las emociones humanas, no se plantea la posibilidad de que las máquinas sientan afecto, sino que puedan imitarlo, principio planteado por Asimov hace varias décadas.

En este punto es relevante mencionar que, aunque en la película sí se plasma que la habilidad del sistema operativo Samantha consiste en la capacidad de imitación de diálogo humano, los participantes consideran que es imposible relacionarse con una máquina, atribuyendo en todo caso la posibilidad a una lejana capacidad de las máquinas de sentir o expresar afecto realmente. Solo una de las participantes llegó a mencionar que había notado que uno de sus hermanos pequeños sentía afecto real por su consola de videojuegos, algo que dentro del intercambio de ideas se tomó más en el sentido cómico. 
En cuanto a la adicción a un dispositivo o la interacción virtual sobre la interacción cara a cara, los 12 participantes sí consideraron que es un problema actual en el que sí están involucrados y lo viven a diario, aunque no perciben consecuencias graves por el momento, atribuyendo el control o la fuerza de voluntad individual como principal factor para que el problema no 'los rebase'.

También llama la atención que 9 de los 12 participantes están convencidos que de alguna manera es 'más fácil' interactuar de forma virtual que presencialmente y que esta interacción puede ser permanente, aunque también afirman que valoran (aún) más a las interacciones cara a cara, donde colocan las relaciones familiares principalmente. Algunos, principalmente los que se encuentran casados, afirmaron que las interacciones virtuales han causado problemas en sus relaciones de pareja, sintiéndose en algunos casos ignorados a causa del uso excesivo de los dispositivos de sus parejas.

Su percepción coincide en cierta medida en los planteamientos de Ruelas (2013), quien señala que los dispositivos móviles están siendo utilizados como instrumentos de privatización de espacios públicos y a su vez los espacios privados se están perdiendo por la gran cantidad de interferencias causadas por estos equipos.

Subraya que estos dos espacios no son los únicos que difuminan sus límites. Por un lado, se encuentra la transformación de la conducta de las personas en relación a los espacios, en específico entre lo laboral y el entretenimiento y por otro, la pérdida de identidad por el ingreso de la tecnología en especial del teléfono celular.

En ese sentido, fueron capaces de identificar estas transformaciones de conducta y la pérdida de identidad en el espacio virtual. La totalidad de los estudiantes se identificó con los personajes 'ignorados' (Amy y Catherine principalmente), en ningún caso con los 'adictos' a la tecnología o que ignoran a los demás. Como comentario adicional, nadie, en ningún caso, se percibió identificado con el protagonista. Lo anterior, con la consideración de que en el primer instrumento todos hablaron en alguna medida sobre el desperdicio de tiempo que generan los dispositivos como algo negativo en su cotidianidad, es decir, el problema es identificado, es cotidiano y se padece, pero no se asumen como generadores del mismo.

Más de la mitad de los estudiantes respondieron que una de las desventajas de la comunicación virtual era no conocer los tonos de voz y las expresiones de las personas con quienes están interactuando, precisamente el punto de partida del sistema operativo Samantha en la trama, su capacidad de imitar expresiones y tonos de voz. 
Las desventajas y ventajas que ubican los jóvenes estudiantes coinciden en cierta medida con lo planteado por Sosa (2019). Las respuestas recogidas dejan ver que el tiempo invertido en el espacio virtual o con los dispositivos se da principalmente para entretenimiento, no para relaciones laborales, académicas o familiares. En cualquier momento, por breve que sea, 'se puede escapar' y distraerse. En este sentido hay ciertas contradicciones en sus respuestas. Por ejemplo, ven como ventaja la posibilidad de comunicarse con familiares cercanos, mientras afirman que con el uso de esta tecnología cada vez hay menos interacción familiar.

Además de considerar tiempo desperdiciado como una desventaja, casi en todos los casos, una parte significativa habló de ser vulnerables a ataques de terceros, una especie de cyberbulling, sin embargo, nunca hablaron de ponerse en estado de vulnerabilidad por sí mismos, sino por 180 acciones de alguien más. No identificaron consecuencias más allá de estos dos factores negativos: tiempo y vulnerabilidad externa. Ninguno, como en el caso de identificarse con los personajes con problemas de adicción, se asumió como alguien que vulnere, sino vulnerado.

\section{Conclusiones}

El uso del cine en particular y los medios audiovisuales en general como recurso didáctico, hoy más que nunca es factible por la masificación y la proliferación del streaming, al que se tiene acceso tanto de forma gratuita como en formatos de pago. El uso de estos productos, que tiempo atrás se podía percibir como un distractor o un enemigo natural de la educación formal, actualmente puede ser concebido como un elemento que también educa, por supuesto, desde una perspectiva crítica y sistemática, teniendo propósitos específicos.

En este caso, el diseño metodológico sustentado en la propuesta de Pérez-Millán para el análisis de contenido audiovisual y el utilizar a los imaginarios sociales en una perspectiva constructivista del aprendizaje, ha permitido, como se pudo constatar, aproximarse a cómo un grupo de jóvenes estudiantes percibe su realidad, en este caso, en relación al uso y abuso de la tecnología.

Si bien los estudiantes no profundizaron sus discusiones con las implicaciones centrales de la inteligencia artificial, la película Her como detonador sí fue un enlace productivo para conocer sus imaginarios sociales respecto a lo que observaron. Está claro lo que ubican como negativo en el abuso de los dispositivos, lo que padecen a partir de esto, pero 
también lo que niegan o al menos asumen que no se aplica con ellos. Sin duda, además de conocer estos imaginarios, esto nos da pauta para abordarlos desde lo escolar con más profundidad.

En esta intervención ha quedado evidenciado que es posible aproximarse a la percepción de grupos específicos respecto a cómo interpretan ciertas realidades, como lo plantean diversos autores que abordan los imaginarios sociales, en este caso: estudiantes de nivel licenciatura familiarizados con el uso de tecnología. Esto nos da pautas no únicamente para conocer su percepción de la realidad, sino para reflexionar sobre cómo pueden intervenir en ella, tarea fundamental para quienes están inmersos en el ámbito educativo.

Aunque en esta intervención se recurrió a una sola narrativa en particular, la propuesta es extrapolable. Las narrativas audiovisuales nos educan, nos guían y nos inducen, generalmente de forma inconsciente y fuera del espacio escolar, a construir los imaginarios sociales que paulatinamente vamos naturalizando y proyectando. En otras palabras, no solo reflejan nuestra realidad, sino que la construyen, de ahí la enorme pertinencia en el plano educativo y científico de adentrarse a su análisis para poder realizar transformaciones.

\section{Bibliografía}

ABRAMS, Jeffrey (productor y director)

2009 Star Trek [Película]. EUA: Bad Robot; Spyglass Entertainment; Paramount Pictures.

ADAMSON, Andrew (director)

2005 The Chronicles of Narnia: The Lion, The Witch and the Wardrobe [Película]. EUA: Walt Disney Pictures; Walden Media.

CAMERON, James (director)

1984 Terminator [Película]. EUA: Pacific Western; Hemdale Film Corporation.

CUARÓN, Alfonso (productor y director)

2013 Gravity [Película]. EUA: Warner Bros.; Esperanto Filmoj; Heyday Films.

DEL TORO, Guillermo (director)

2006 El laberinto del Fauno [Película]. España-México: Estudios Picasso; Tequila Gang; Telecinco; Sententia Entertainment.

JONZE, Spike (director)

2013 Her [Película]. EUA: Warner Bros.

KUBRICK, Stanley (productor y director)

1968 2001: A Space Oddysey [Película]. RU-EUA: MGM; Stanley Kubrick Production.

LIMAN, Doug (director)

2014 Edge of Tomorrow [Película]. EUA: Warner Bros.; 3 Arts Entertainment; Viz Media. 
MEJÍA, José \& NAHMAD, Ana

2017 Discusión teórica I y II de cine de no ficción [Archivo de video]. En Usos didácticos del cine: introducción al análisis. México DF: UNAM.

NOLAN, Christopher (director)

2014 Interestelar [Película]. EUA: Warner Bros.; Syncopy Production; Paramount Pictures; Legendary Pictures.

2011 (productor y director). Inception [Película]. RU-EUA: Warner Bros.; Legendary Pictures; Syncopy Production.

PÉREZ-MILLÁN, Jorge

2014 Cine, enseñanza y enseñanza del cine. Madrid: Morata.

PINTOS, José

2015 Apreciaciones sobre el concepto de imaginarios sociales. Miradas: Revista de Investigación, 13, 150-159. Universidad Tecnológica de Pereira, Colombia.

RANDAZZO, Francesca

2012 Los imaginarios sociales como herramienta. Revista Imagonautas, 2(12). Recuperado de https://bit.ly/37lcYzE/

RUELAS, Ana

2013 El teléfono celular: su incorporación a la vida social. México DF: Juan Pablos Editor.

SCOTT, Riddley (director)

2001 Gladiator [Película]. RU-EUA: Universal Pictures; DreamWorks SKG.

2015 The Martian [Película]. EUA: 20th Century Fox; Scott Free; TSG Entertainment.

SINGER, Bryan (director)

2018 Bohemian Rhapsody [Película]. RU-EUA: GK Films.

SOSA, Dolores

2018 Relaciones interpersonales entre los jóvenes universitarios y los espacios de presentación virtual. Ponencia del XII Simposio Internacional Educación y Cultura, La Habana, Cuba.

SPIELBERG, Steven (director)

2001 A.I. [Película]. EUA: Warner Bros.; DreamWorks SKG; Amblin Entertainment; Stanley Kubrick Production.

2012 Lincoln [Película]. EUA: 20th Century Fox; DreamWorks SKG; Amblin Entertainment.

SPUTORE, Grant (director)

2019 I Am Mother [Película]. Australia: Penguin Empire; Rhea Films; Southern Light Alliance; Southern Light Films.

TARANTINO, Quentin (director)

2009 Inglourious Bastards [Película]. EUA-Alemania: Universal Pictures; Weinstein Company.

TORRES, Manuel

2015 La evolución del concepto de imaginarios sociales en la obra publicada de Juan Luis Pintos de Ceha Naharro. Revista Imagonautas, 6, 1-14.

TYLDUM, Morter (director)

2014 The Imitation Game [Película]. RU: Black Bear Pictures; Ampersand Pictures. WOOD, David \& GUDIÑO, Rosa

2017a Introducción al cine educativo [Archivo de video]. En Usos didácticos del cine: introducción al análisis. México DF: UNAM. 
WOOD, David \& GUDIÑO Rosa

2017b Antecedentes del cine educativo [Archivo de video, parte 1]. En Usos didácticos del cine: introducción al análisis. México DF: UNAM.

WOOD, David \& GUDIÑO Rosa

2017c Antecedentes del cine educativo [Archivo de video, parte 2]. En Usos didácticos del cine: introducción al análisis. México DF: UNAM.

ZEMECKIS, Robert (director)

1997 Contact [Película]. EUA: Warner Bros.

Fecha de recepción de documento: 15 de julio de 2019

Fecha de revisión de documento: 20 de septiembre de 2019

Fecha de aprobación de documento: 15 de noviembre de 2019

Fecha de publicación de documento: 15 de enero de 2020 